\title{
Reflections on Pandemics, Civil Infrastructure and Sustainable Development: Five Lessons from COVID-19 through the Lens of Transportation
}

Adjo Amekudzi-Kennedy, Ph.D. ${ }^{1}$ | Samuel Labi, Ph.D. ${ }^{2}$ Brian Woodall, Ph.D. ${ }^{3}$ | Mikhail Chester, Ph.D. ${ }^{4} \mid$ Prerna Singh ${ }^{5}$

April 3, 2020

\begin{abstract}
Humanity's social and economic development has been challenged by a range of adversities over the millennia that have caused widespread and unimaginable suffering. At the same time, these challenges have forced humans to evolve more wisely, overcoming adversity through creativity and leading to advancements in science and technology, medicine, ethics and legal systems, and socio-political systems. The dynamics of risks and opportunities caused by COVID-19, in the built, cyber, social and economic environments, present opportunities for deepening our understanding of resilient and sustainable development and infrastructure. This article reflects on five lessons that COVID-19 is teaching us about what it means to develop sustainably through the lens of transportation: (1) sustainable development planning and analytical frameworks must be comprehensive, for long-term sustainability; (2) multi-modal transportation is a superior vision for sustainable development than any one particular mode; (3) tele-activities are part of an effective infrastructure sustainability strategy; (4) economic capital is critically important to sustainable development even when it is not a critical existential threat, and, (5) effective social capital is essential in global disaster resistance and recovery, and can and must be leveraged between fast-moving and slow-moving disasters. Resilient and sustainable infrastructure will continue to be critical to addressing evolving natural and man-made hazards in the $21^{\text {st }}$ Century.
\end{abstract}

\section{KEYWORDS}

Sustainable development, System resilience, Resilient and sustainable infrastructure, Pandemics, COVID19

\section{INTRODUCTION}

Since the dawn of time, the social and economic development of humans has been challenged by adversities including war, famine, genocide, epidemics, and natural disaster. While these catastrophes have exacted unimaginable toll in terms of pain, suffering and loss on the human race at different points in time, they have also forced humans to evolve wisely. To various extents, societies have made efforts to develop in ways that neither precipitate nor foster these occurrences directly or indirectly; they have also endeavored to be more resilient to such future occurrences should they occur. Several notable advancements in science and technology, medicine, ethics and legal systems, and socio-political systems arose in response to terrible human suffering caused by natural or anthropogenic events. Therefore, each occurrence of these adverse events offers opportunities for society to make mid-course corrections as we continue to develop - sustainably or otherwise. Humans have tended to overcome adversity through creativity. However, in a few cases, these opportunities have been missed, for various

\footnotetext{
${ }^{1}$ Professor, School of Civil \& Environmental Engineering, Georgia Institute of Technology, Atlanta, GA

2 Professor, Lyles School of Engineering, Purdue University, Lafayette, IN

${ }^{3}$ Professor, Sam Nunn School of International Affairs, Georgia Institute of Technology, Atlanta, GA

${ }^{4}$ Associate Professor, School of Sustainable Engineering \& the Built Environment, Arizona State University, AZ

${ }^{5}$ Ph.D. Candidate, School of Civil \& Environmental Engineering, Georgia Institute of Technology, Atlanta, GA
} 
reasons including lack of knowledge or awareness, lack of political will, funding problems, corrupt practices, or institutional or social inertia. Often, thoughtful reflections on the issues can provide useful pathways to overcoming some of these challenges.

At different geographic locations and times, varied definitions of sustainable development have been adopted, leaving many wary of the term "sustainable development", wondering about its apparent lack of consistency and practical relevance. Examination of the peer-reviewed and popular literature reveals a preponderance of sustainable development definitions that focus more on the natural environment in the Global North, and more on social and economic development in the Global South (e.g., see Yazdani \& Dola 2013) - valid operational definitions in their respective contexts. When we consider sustainable development from the perspective of managing a community's resources as a portfolio of assets in the long term, the concepts of a sustainable development risk and a sustainable development opportunity make sense. We also understand that the risks and opportunities associated with a community's sustainable development trajectory may vary over time, and at any given time, these risks and opportunities may differ across various geographic locations (Amekudzi-Kennedy et al. 2015).

Arguably the most cited and applied model for sustainable development, the Triple Bottom Line (TBL) model is broadly evident in conceptual definitions of sustainable development (e.g., see UN 1987, ASCE 2009) - indicating we may appropriately consider social, environmental and economic resources (i.e., capital) when planning for and implementing projects and programs to advance sustainable development. Indeed, when communities are planning for sustainable development, they are better off considering all the different types of capital (including but not limited to the TBL) that are necessary for sustainable development within their local contexts - to ensure they create superior sustainable development plans, clarify the existing inter-capital tradeoffs, and understand the opportunity costs of various development scenarios (Amekudzi-Kennedy, et al. 2015). Thus, communities may appropriately expand on the TBL capital to include built environment, cyber and other capital considerations, where these are critical factors for or threats to sustainable development (Jeon \& Amekudzi 2005). When we examine them more closely, we typically find that these different types of capital are inevitably and inextricably linked. We may also realize that existential threats (e.g., climate and man-made hazards) to the resilience of several of our sociotechnical systems (e.g., water treatment and energy plants, building facilities, transportation systems, and others) pose risks to sustainable development. In this regard, the infrastructure sustainability-resilience nexus highlights the important two-way relationship between infrastructure and the surrounding economic, social and environmental elements - requiring infrastructure that minimizes adverse impacts while maximizing (a) the beneficial impacts of our infrastructure to these elements of sustainable development; and, (b) the beneficial impacts from these elements to our infrastructure systems (Labi 2014).

\section{THE LESSONS}

COVID-19 offers many lessons on sustainable development, if we are willing to learn. Below, we discuss five lessons on infrastructure and sustainable development relative to the pandemic, by no means exhaustive - but revealing of what it means to develop sustainably, in the long term: (1) sustainable development planning and analytical frameworks must be comprehensive, for long-term sustainability; (2) multi-modal transportation is a superior vision for sustainable development than any one particular mode; (3) tele-activities are part of an effective infrastructure sustainability strategy; (4) economic capital is critically important to sustainable development even when it is not a critical existential threat, and, (5) effective social capital is essential in global disaster resistance and recovery, and can and must be leveraged between fast-moving and slow-moving disasters. 


\section{(1) Sustainable development planning and analytical frameworks must be comprehensive, for long- term sustainability}

Extensive portions of the peer-reviewed literature on sustainable development focus on carbon emissions as the critical risk to sustainable development and promulgate strategies to curb carbon emissions in order to reduce the carbon footprint. This is important and useful. COVID-19, however, shows how the critical risks to sustainable development may change as critical existential threats change. The appearance and rapid spread of the Coronavirus has come with quick and mass movement away from mass transit as communities have sought to reduce their risks of contracting the virus. As physical distancing has become global social policy, a large portion of personal physical mobility has in the course of a few weeks shifted online. This is playing out in terms of telework and tele-schooling largely, but also in online shopping and online recreation. Once touted as a most sustainable form of transportation - that is, from the standpoint of per capita energy consumption and carbon emissions, it is clearer to many today that mass transit may itself become a critical risk to sustainable development. On March 17, 2020, the New York Times reported that New York City's public transportation system, the largest in North America, is seeking a \$4 billion federal bailout as the coronavirus pandemic has triggered an extraordinary free fall in ridership (i.e., $60 \%$ on the subways, and as much as $90 \%$ on the commuter railways), and left transit officials facing what is likely to be the worst economic crisis in decades (Goldbaum 2020). The New York Times also reported that ridership on the Bay Area Rapid Transit was down $70 \%$ on Monday (that week), compared with an average Monday last month, and that was before residents began a three-week period of sheltering at home on Tuesday, leaving only to fulfill essential needs because of instructions from public health authorities (Taylor 2020). Mass transit experiences nationwide, and worldwide, reflect how public health risks such as the Coronavirus (i.e., a social capital-related risk) may soon have cascading effects on the economy and generate economic risks (i.e., economic capital-related risks) to developing sustainably. They highlight the critical importance of formally considering all the triple bottom line capital, not only the critical risks to sustainable development at any particular time, in addition to other contextually pertinent capital, as well as natural and man-made risks to resilience - when planning for sustainable development.

\section{(2) No single mode of transportation is superior in the long-term; all modes together elevate system resilience and thus contribute to long-term sustainable development}

Second, the coronavirus pandemic has highlighted that effective multimodal transportation is more resilient and thus key to developing sustainably. "Across the country, cities with public transit systems are being forced to adapt to the risks posed by the coronavirus. While carrying out stringent sanitation protocols, and amid a major decline in ridership, transit officials must also balance discouraging people from riding and reassuring those who have no other transportation options that their buses and trains are safe" (Taylor 2020). We have watched the automobile, which has long been considered an unsustainable means of transportation, when evaluated on its carbon-based energy consumption and emission, become a safer and more sustainable mode of transportation in the context of a pandemic such as COVID-19. At the same time, a large percentage of the world's population is dependent on public transportation for travel. COVID-19 is teaching us that perhaps it is not so much about one mode versus another, or which transportation mode is the best from only one perspective (e.g., environmental) or a limited set of perspectives; but rather that there is wisdom in planning for and investing in a robust multimodal transportation system that offers multiple convenient and costeffective choices - allowing for populations to make the choices that best support their needs through wide-ranging scenarios (Fischer \& Amekudzi 2011). This kind of thinking will lead to a more resilient transportation system in the long run - resilient to various existential threats that will surface in time. 
"With a virus that is extremely contagious, public transit systems have emerged as a focus of concern, each having enclosed spaces and surfaces where the coronavirus can linger for days if they are not sanitized. Drivers, too, are concerned about their potential exposure to the virus, and transit officials have worried about how they would function if a large number of workers are infected and unable to work" (Taylor 2020). From the viewpoint of system resilience, the ability to prepare and plan for, absorb, recover from, or more successfully adapt to adverse events (NRC 2012), it is clear that a multimodal transportation system - consisting of effective automobile transport (not hampered by debilitating congestion nor environmentally-unsustainable fuels), effective public transit, effective nonmotorized transportation (i.e., walking and biking), urban air transport, and other non-traditional and traditional modes - ultimately emerges as a superior vision for transportation for long-term system resilience. As we move forward into the $21^{\text {st }}$ Century, expanding community choices in a cost-effective, equitable and resilient manner should undergird our planning for sustainable systems. This would necessitate a move away from traditional benefit-cost analysis as an exclusive analytic framework for planning and decision making to multi-objective approaches that value system resilience, e.g., redundancy, robustness, adaptive capacity, and system sustainability simultaneously with economic optimization - even though this will sometimes present conflicting objectives.

\section{(3) Tele-activities are part of an effective infrastructure sustainability strategy}

COVID-19 has made it possible for the U.S. and the global community to obtain a glimpse into the potentially significant positive impacts of teleworking and tele-schooling on infrastructure demands and sustainable development. A majority of the demand for transportation every weekday is for work and school trips - with most workers and students taking to the nation's highways and mass transit systems at least 10 times per week. The movement of the nation at large to teleworking and tele-schooling during the COVID-19 pandemic is causing many to ask questions about how essential it is to travel back and forth on a daily basis for work and school. This shift has been enabled by the largely scale free nature of the internet and its multi-functionality (Chester and Allenby 2019). The pandemic combined with a mature and accessible internet, in several places, is making us more open to exploring alternatives to the status quo before COVID-19. According to Kate Lister, president of Global Workplace Analytics (GWA), the billion-dollar question is how many people will become remote workers after the dust settles on COVID-19. GWA, one of the nation's authorities on work-at-home, estimates that " $56 \%$ of the U.S. workforce holds a job that is compatible (at least partially) with remote work. We know that currently, only $3.6 \%$ of the employee workforce works at home half-time or more. Gallup data shows that $43 \%$ of the workforce works at home at least some of the time." They predict that the longer people are required to work at home, the greater the adoption we will see when the dust settles. Based on historical trends, GWA believes that those who were working remotely before the pandemic, will increase their frequency of working at home after they are allowed to return to their offices. They also believe that there will be a significant increase in adoption of work-at-home practices for those who were new to remote work until the pandemic.

GWA-estimates that we will see $25-30 \%$ of the workforce working at home on a multiple-days-aweek basis within the next two years for several reasons: (1) Reduced concern of managers and executives (as one of the biggest holdbacks to remote working has been trust - trust that employees are really working at the same levels as they are when they are physically in their offices.); (2) Increased pressures for disaster preparedness (COVID-19, and all of the work disruption it has caused, will not soon be forgotten by organizational leaders, shareholders, or other stakeholders. Those who were not ready this time will learn what worked and what didn't work and will be compelled to close 
the gaps so they are better prepared in the future.); (3) Increased awareness for cost-saving opportunities (While the primary driver of work-at-home programs has been the attraction and retention of talent over the past several years, during the last recession, it was largely about saving money. Organizational leaders, anxious to reduce costs, found they could do more with less real estate. Since that time, occupancy studies have shown just how inefficiently office space was being used. Employees around the globe are not at their desk $50 \%$ to $60 \%$ of the time, a huge waste of money.); (4) Increased awareness of the potential impact on sustainability (Even in the early days of global response to COVID-19, there is a dramatic reduction in traffic, congestion and pollution. It is becoming clear that that while sustainability has not been a primary driver for work previously, remote work can have a substantial impact on carbon footprint reduction in the global community.); and, (5) Reduced business travel (While remote meetings may not have all the same benefits as virtual meetings, the benefits may far outweigh the costs - with estimates of over $\$ 30$ Billion/day savings from work-at-home for U.S. employers. A typical employer can save about $\$ 11,000 /$ year for every person who works at home half of the time (Lister 2020).

One of the National Science Foundation's (NSF) 10 big ideas is the future of work at the humantechnology frontier. In light of the lessons emerging from COVID-19, the future of work at the human-technology frontier can have very important ramifications with respect to changing needs for building and transportation infrastructure in cities and communities across America. These reduced demands, if they continue, will come with opportunities to address persistent urban resilience risks such as metropolitan congestion, unbridled floodplain development and other man-made and climate hazards, and sustainable development threats, through infrastructure renewal. As Haskel and Westlake acknowledge in their book "Capitalism without Capital" (2018), the rise of the intangible economy will mean a significant percentage of economic value created in the future will be intangible. Judging from the emerging lessons from COVID-19, a significant percentage of this value may also be created intangibly via the human-technology interface in the future of work and school. COVID-19 has shown us the criticality of cyberinfrastructure for continued operations in pandemic situations and should prompt communities in the U.S. and around the world to think seriously about the correlation between cyber-maturity (i.e., the level of a community's cyber capabilities, access and security, which involves addressing the digital divide) and social and economic productivity and resiliency. Continued advancements in the digital revolution and elimination of the digital divide should increasingly be viewed as economic development opportunities, social quality of life (QOL) development opportunities (including public health), system resilience development opportunities and thus sustainable development opportunities for communities around the nation and around the world.

(4) Economic capital is critically important to sustainable development even when it is not a critical existential threat

The importance of economic capital as a critical factor in developing sustainably is evident in the fight against COVID-19. We touched upon this briefly in our discussion on the cascading effect of the Coronavirus on mass transit, above. The effect of the pandemic on jobs (i.e., reduction and loss), and the ability of individuals, families and businesses to pay their bills, reflects the critical importance of economic self-sufficiency at all scales for sustainable development. On March 27, 2020, the U.S. Congress passed the historic coronavirus economic relief bill including checks for individuals and families and loans for businesses totaling \$2 Trillion, which was subsequently signed into law (Zeballos-Roig 2020). The far-reaching legislation stands as the largest emergency aid 
package in U.S. history, and represents a massive financial injection into a struggling economy with provision to help American workers, small businesses and industries grappling with economic destruction (Foran et al. 2020). While the critical risk in this crisis was originally the Coronavirus (i.e., a public health risk, social-capital related), the effects of this existential risk have begun to show on the economy - as is typical with sustainable development risks (Amekudzi-Kennedy et al. 2015) - in ways that may result in economic capital becoming the existential risk for many individuals, families and businesses. Communities at all scales (i.e., municipalities, nations, regions and others) that possess robust economic capital and thus are economically resilient can afford to make such financial infusions to curb economic risks while efforts continue to manage the pandemic and find a vaccine and/or cure. Communities without such levels of economic capital cannot afford to support such financial infusions and may find themselves vulnerable to severe economic disruptions, and their economy, in some cases, may pivot to become the critical existential threat.

This dynamic may be observed in various disaster situations, e.g., climate-related disasters, where history has shown that more economically affluent municipalities, states and regions are more able to make the necessary economic investments to bounce back relatively more quickly from disasters and vice versa. Thus, economic capital cannot be taken for granted in the quest for sustainable development. Clearly, definitions of sustainable development that exclude economic capital are, at best, incomplete. Communities that develop and store economic capital for a rainy day are also strengthening their resilience to disasters, in the short term and the long term, as can be seen in the COVID-19 dynamics of public health and economics. Ultimately, social, economic and environmental capital - including social equity - interact to support or retard sustainable development, and strategic planning and implementation of policies, programs and projects to augment all three types of capital are also efforts to strengthen resilience and improve QOL in a sustainable manner. It stands to reason then that economic development, in a socially equitable manner, is also development to strengthen a community's resilience to disasters - be they rapid or slow-moving disasters. Such economic resilience enables communities to preserve the viability of large-scale infrastructure, such as mass transit systems, with bailouts in seasons when they are less financially viable (e.g., during pandemics) for other seasons when the critical existential threats shift to other factors, e.g., carbon-based energy consumption and emissions, and their value is once again evident.

(5) Effective social capital is essential in global disaster resistance and recovery - and can and must be leveraged between fast-moving and slow-moving disasters

Finally, COVID-19 has demonstrated the importance of the global community mobilizing and acting quickly around common sustainable development risks - with rapidity and resolve. Gardiner (2020) reports that several parallels have been drawn between fast-moving disasters like COVID-19 and slowmoving disasters like climate change, in particular the need to act quickly to gain control over the situation. In Gardiner's article, Elizabeth Sawin, co-director of Climate Interactive, a think tank, notes that "while the disease is playing out more quickly than the effects of global warming, the principle is the same. If you wait until you see the impact, it is too late to stop it." Further, according to Gernot Wagner, a climate economist at New York University: "COVID-19 is climate on warp speed. Everything with climate is decades: here it's days. Climate is centuries; here it's weeks." Wagner also notes that governments' responses have morphed almost as fast as the threat. He notes that we are watching our political leaders learn these lessons live on TV, within days. "That's a learning curve we have never seen with anything, at least not in my lifetime." (Gardiner 2020). The United Nations' Sustainable Development Goals (SDGs) acknowledge the critical importance of partnerships as a necessity for 
achieving all the SDGs. The $17^{\text {th }}$ SDG calls for strengthening the means for implementation and revitalizing the global partnership for sustainable development (UN 2018). The collaborations and partnerships that have been formed, some very rapidly, to fight COVID-19 must signify to all that it is possible for the global community to come together quickly and with resolve to seek, find and implement solutions to common sustainable development challenges - particularly when these challenges are existential in nature and are playing out rapidly. We must take advantage of the windows of opportunity surrounding and following crises to highlight the similarities between fast moving disasters such as COVID-19 and slow moving hazards such as climate change, debilitating metropolitan highway congestion, unbridled floodplain development, and other sustainable development risks. We must also highlight that pre-existing partnerships, and those developed rapidly around catastrophic disasters, may all be leveraged in our fight against climate change and other common slower-moving disasters - globally and locally.

\section{CONCLUDING REMARKS}

The COVID-19 pandemic may be unprecedented in its global scope and the intensity of its socioeconomic impacts. Yet still, it is only one link in the long chain of man-made or natural catastrophes that have plagued the human race over the millennia. It could be the case that we will experience an increasing frequency of such events in the future. For example, a number of scientists have postulated that the incipient climate change is causing increased interactions between humans and animals in ways that will further expose each of these two categories of species to danger, particularly to the transfer of diseases. In general, as we face the challenges of the current era and foreseeable future, we must learn to adapt quickly to the changes of the times. In particular, as stewards of engineered infrastructure and the social and natural environments, we must continue to perform in our traditional roles while innovating in designing, operating, and maintaining our physical and physical-cyber systems simultaneously as we adapt them to be resilient to natural and man-made hazards. We must increasingly be cognizant of the two-way interactions of these systems, and the natural and man-made environments (including societal, economic, natural, and personal health) and their associated and changing hazards. With keen awareness of these issues, a healthy dose of optimism, and a penchant for innovation, we may stay ahead of curve posed by adversities associated with society, and with the natural, economic, built, and cyber environments.

\section{REFERENCES}

Amekudzi, A. A., Khisty, C. J., and M. Khayesi. Sustainable Development Footprint: A Framework for Assessing Sustainable Development Risks and Opportunities in Time and Space. International Journal for Sustainable Development, Vol. 18, Nos. 1/2, 2015, pp. 9 - 40.

American Society of Civil Engineers (ASCE). Board Approved Definition of Sustainable Development. From ASCE Committee of Sustainability Meeting Agenda, November 15, 2010. First Green Highways and Streets Conference, Denver, CO, United States.

Chester, M., and B. Allenby. Toward adaptive infrastructure: flexibility and agility in a non-stationary age. Sustainable and Resilient Infrastructure, Vol. 4 (4) 2019. http://dx.doi.org/10.1080/23789689.2017.1416846

Fischer, J., and A. Amekudzi. Quality of Life, Sustainable Civil Infrastructures and Sustainable Development. Strategically Expanding Choice. ASCE Journal of Urban Planning and Development, American Society of Civil Engineers, Vol. 137, Issue 39, March 2011, pp. 39-48.

Foran, Clare; Raju, Manu; Byrd, Haley; Barrett, Ted; and Wilson, Kristin. Trump signs historic \$2 Trillion stimulus after Congress passes it Friday. CNN politics. March 27, 2020. https://www.cnn.com/2020/03/27/politics/coronavirusstimulus-house-vote/index.html Accessed March 2020.

Gardiner, Beth. Coronavirus Holds Key Lessons on How to Fight Climate Change. YaleEnvironment $\underline{360}$. Published at Yale School of Forestry and Environmental Studies. https://e360.yale.edu/features/coronavirus-holds-key-lessons-on- 
how-to-fight-climate-change?fbclid=IwAR3LmCT2WTq pE3YxzeFZczrDckW2Ef-6herkU6gA0R1BwnIJzyFxaw0mfU Accessed March 2020.

Haskel, J., Westlake, S. Capitalism without Capital - The Rise of the Intangible Economy. Princeton University Press, N.J., 2018.

Jeon, C.M., and A. Amekudzi. Addressing Sustainability in Transportation Systems: Definitions, Indicators and Metrics. ASCE Journal of Infrastructure Systems, American Society of Civil Engineers, Vol. 11, No. 10, March 2005, pp. 31-50.

Labi, Samuel. Introduction to Civil Engineering Systems: A Systems Perspective to the Development of Civil Engineering Facilities. 2014. John Wiley\& Sons.

Lister, Kate. Work-At-Home After Covid-19 - Our Forecast. Global Workplace Analytics. <https://globalworkplaceanalytics.com/work-at-home-after-covid-19-our-forecast> Accessed March $29,2020$.

National Research Council. Disaster Resilience. A National Imperative. The National Academies. The National Academies Press, 2012: Washington, D.C.

Taylor, Kate. No Bus Service. Crowded Trains. Transit Systems Struggle With the Virus. The New York Times. Published March 17, 2020.

Goldbaum, Christina. M.T.A. Citing Huge Drop in Riders, Seeks \$4 Billion for Virus Bailout. The New York Times. Published March 17, 2020.

United Nations. Transforming our world: the 2030 Agenda for sustainable Development. A/RES/70/1, New York, 2015. United Nations. Report of the World Commission on the Environment and Development: Our Common Future. 1987. Yazdani, Saeid; and, Dola, Kamariah. Sustainable Cities Priorities in Global North Versus Global South. Journal of Sustainable Development, 2013, Vol. 6 (7): 38-47.

Zeballos-Rog, Joseph. Trump signs corona virus economic relief bill into law, which includes checks for Americans and Business Loans. Business Insider, March 27, 2020. https://www.businessinsider.com/trump-signs-coronaviruseconomic-relief-aid-bill-checks-for-americans-2020-3, Accessed March 2020. 